\title{
Care pathways
}

\section{John Launer}

If you can afford to pay up to $£ 18$ a day to use the main car park, you may be lucky enough to spot the sign to the main entrance of the hospital. If you come by public transport, however, you will have to ask the bus driver where to get off because the nearest stop is about 10 min walk away, by the hospital's back entrance. Even when you are off the bus, you can struggle to find it because it is barely signposted. Your best bet is to follow other people, mainly elderly, as they wait patiently by the pedestrian crossing for the lights to change and then stumble their way across as hastily as they are able.

At the back entrance there is a large sign saying "Accident and Emergency Only: No Access to Main Hospital". Fortunately you will sometimes find a security guard there who will point you towards a small unmarked door that leads to a connecting corridor. Inside the corridor, there is at least a helpful arrow saying "All Departments". As you walk down the corridor, you notice various assorted signs. For example, there is a yellow plastic sign saying "Neuro-radiology", an ancient painted one saying "Theatre staff only", and a piece of A4 paper stuck on with Blu-Tack saying "HR department turn left". There are also doors and staircases with no notices at all. Nowhere is there a map.

Eventually you come across a sign to "Oncology Reception". Although that is not your destination, at least it leads you to expect someone helpful at the desk. Alas, the young woman is clearly annoyed at being used all the time as a general information bureau. She responds to your request for directions by inquiring sarcastically why you didn't come in at the main entrance and ask there. Grudgingly, she tells you that you can reach your destination by going down the stairs behind you and following signs to "Block B".

The stairs take you down to a bleak corridor with heating pipes along it. There are stray items abandoned along it including hospital trolleys and antique wheel chairs. At the end of the corridor is another set of stairs, leading up to a large yard. One side of the yard consists of the original Victorian workhouse that still

Correspondence to: Dr John Launer, London Department of Postgraduate Medical Education, Stewart House, 32 Russell Square, London WC1B 5DN, UK; jlauner@londondeanery.ac.uk contains some of the old wards. On the other side of the yard is a ramp leading to a 1980s tower block. The concrete is stained and pitted and the block already looks more dilapidated than its 19th century neighbour. Elsewhere around the yard you can see several portakabins, a building site with a crane, and piles of rubble. But there are no further signs showing where you might find Block B.

\section{HOSPITAL VISITS}

Every week I visit at least one hospital in the course of my work. On almost every occasion I have an experience similar to the one above. The description I have given has been combined from several recent visits, and represents the average. Sometimes things are slightly better and sometimes they are worse, but I almost never regret giving myself an extra half hour to find the venue for my meeting. It is surprising how often there is no public transport taking you direct to the main entrance. The lack of thoughtful and consistent signposting is almost universal, and so is architectural disorder ranging from inconsistency to absolute chaos. Sadly, it is also a regular experience to meet reception staff who are abrupt or rude when asked for information outside their paid remit.

One thing that strikes me about these experiences is the lack of imagination they represent on the part of some managers. If a visitor like myself-healthy, alert, unrushed, and on official NHS business-finds myself disoriented and upset, what on earth must it be like for someone older, frail, anxious, unwell, and late for an outpatient appointment? Alongside a failure of imagination, I suspect there is a failure of responsibility too. I wonder how many hospitals could identify a single person who is responsible for making the overall experience of the visitor a tolerable one. Surely someone could wander around any hospital now and again with an observant eye-or even accompanied by an outsider-to make sure that everything is easy to find, and that topographical muddles are made intelligible through maps, colour codes or other aids.

\section{SHIFTS OF DIRECTION}

Thoughtful managers could no doubt make a lot of difference but the problem goes deeper than management. Almost everything I have described is a symboland often a direct outcome-of the way we approach health and the health service in Britain. The inadequacy of public transport and the scandalous costs of hospital parking are not an accident or a coincidence. They are the results of calculated policy decisions, and a national state of indifference to inequality. The bewildering layout of hospitals simply compounds the difficulty of getting an appointment in the first place, because of waiting lists and scarce resources. The confusion and incoherence of hospital architecture stand as metaphors for inconsistent health policies, sudden shifts of political direction and a lack of long term strategic planning. The rudeness of front line staff, albeit inexcusable, is a token of demoralisation and deprofessionalisation in the public services. Somehow the notion of providing a friendly, caring service to the public has lost out to the opposing idea that patients should be grateful for what they get.

But perhaps the explanation for these experiences lies deeper still. It often strikes me how much hospitals can resemble the diseases they are offering to treat. The peeling walls or disintegrating concrete call to mind eczema or psoriasis. The proliferation of different styles of building, spread around at random, seems like a form of metastasing cancer. The most disorienting hospital I have come across was one of London's last remaining mental hospitals, laid out in locked and unmarked buildings over an enormous acreage of land: it took the best part of an hour to locate anyone there who was expecting me, and who knew why I had come or where I should be going. A patient who was not already feeling depersonalised, fragmented and out of control on arrival there would surely feel that way within a very short time.

Health is indivisible. It must be an illusion to think that we can make people's bodies and minds better irrespective of the environment in which we try to do so. Patients whose moods are affected by the thoughtlessness, ugliness and impoverishment of their surroundings cannot be in a state of mind to join as partners in their treatment. If we want to convince people that we can make them better, we should be able to give them signs-in every sense-that we know where they are coming from, and where they should be going. If we mean to make the patient's journey as painless as possible, we need to start, quite literally, at the bus stop.

Competing interests: None declared.

Postgrad Med J 2008;84:392.

doi:10.1136/pgmj.2008.072314 